\title{
Model Policy for Research Data Management (RDM) at Research Institutions/Institutes
}

\section{PREAMBLE}

The [name of research institution] recognizes the fundamental importance of research data ${ }^{1}$ and the management of related administrative records in maintaining quality research and scientific integrity, and is committed to pursuing the highest standards. The [name of research institution] acknowledges that correct and easily retrievable research data are the foundation of and integral to every research project. They are necessary for the verification and defence of research processes and results. RDM policies are highly valuable to current and future researchers. Research data have a long-term value for research and academia, with the potential for widespread use in society.

\section{JURISDICTION}

This policy for the management of research data applies to all researchers active at the [name of research institution]. The policy was approved by the [dean/commission/authority] on [date]. In cases when research is funded by a third party, any agreements made with that party concerning intellectual property rights, access rights and the storage of research data take precedence over this policy.

\section{INTELLECTUAL PROPERTY RIGHTS}

Intellectual property rights (IPR) are defined in the work contract between a researcher and his or her employer. IPRs might also be defined through further agreements (e.g. grant or consortial agreements). In cases where the IPR belong to the institution that employs the researcher, the institution has the right to choose how to publish and share the data.

\section{HANDLING RESEARCH DATA}

Research data should be stored and made available for use in a suitable repository or archiving system, such as [name of institutional repository/archiving system, if applicable]. Data should be provided with persistent identifiers.

It is important to preserve the integrity of research data. Research data must be stored in a correct, complete, unadulterated and reliable manner. Furthermore, they must be identifiable, accessible, traceable, interoperable, and whenever possible, available for subsequent use. 
In compliance with intellectual property rights, and if no third-party rights, legal requirements or property laws prohibit it, research data should be assigned a licence for open use. ${ }^{2}$

Adherence to citation norms and requirements regarding publication and future research should be assured sources of subsequently-used data explicitly traceable, and original sources can be acknowledged.

Research data and records are to be stored and made available according to intellectual property laws or the requirements of third-party funders, within the parameters of applicable legal or contractual requirements, e.g. EU restrictions on where identifiable personal data may be stored. Research data of future historical interest and the administrative records accompanying research projects should also be archived.

The minimum archive duration for research data and records is 10 years after either the assignment of a persistent identifier or publication of a related work following project completion, whichever is later.

In the event that research data and records are to be deleted or destroyed, either after expiration of the required archive duration or for legal or ethical reasons, such action will be carried out only after considering all legal and ethical perspectives. The interests and contractual stipulations of third-party funders and other stakeholders, employees and partner participants in particular, as well as the aspects of confidentiality and security, must be taken into consideration when decisions about retention and destruction are made. Any action taken must be documented and be accessible for possible future audit.

\section{RESPONSIBILITIES, RIGHTS, DUTIES}

The responsibility for research data management during and after a research project lies with [name of research institution] and its researchers and should be compliant with codes for the responsible conduct of research.

\subsection{RESEARCHERS ARE RESPONSIBLE FOR:}

a. Management of research data and data sets in adherence with principles and requirements expressed in this policy:

b. Collection, documentation, archiving, access to and storage or proper destruction of research data and research-related records. This also includes the definition of protocols and responsibilities within a joint research project. Such information should be included in a Data Management Plan (DMP), or in protocols that explicitly define the collection, administration, integrity, confidentiality, storage, use and publication of data that will be employed. Researchers will produce a DMP for every research proiect.

c. Compliance with the general requirements of the funders and the research institution;

special requirements in specific projects should be described in the DMP:

d. Planning to enable, wherever possible, the continued use of data even after project completion. This includes defining post-project usage rights, with the assignation of

\section{Concrete recommendations tor icensing should be isted and be avaliable to the researchers.}

appropriate licences, as well as the clarification of data storage and archiving in the case of discontinued involvement at the [name of university/research institution]

e. Backup and compliance with all organisational, regulatory, institutional and other contractual and legal requirements, both with regard to research data, as well as the administration of research records (for example contextual or provenance information);

f. To ensure appropriate institutional support, it is required that new research projects are registered at the proposal stage at [name of research institution/central body]

\subsection{THE [NAME OF RESEARCH INSTITUTION] IS RESPONSIBLE FOR:}

a. Empowerment of organisational units, providing appropriate means and resources for research support operations, the upkeep of services, organizational units, infrastructures, and employee education:

b. Support of established scientific practices from the beginning. This is possible through the drafting and provision of DMPs, monitoring, training, education and support, whil in compliance with regulations, third-party contracts for research grants, university/ institutional statutes, codes of conduct, and other relevant guidelines;

c. Developing and providing mechanisms and services for the storage, safekeeping, registration and deposition of research data in support of current and future access to research data during and after the completion of research projects;

d. Providing access to services and infrastructures for the storage, safekeeping and archiving of research data and records, enabling researchers to exercise their responsibilities (as outlined above) and to comply with obligations to third-party funders or other legal entities.

\section{VALIDITY}

This policy will be reviewed and updated as required by the head of/the director of the [name the research institution] every [two years].

\section{Annex: Definitions of Research, Researchers and of Research Data}

1. Research is any creative and systematically performed work with the goal of furthering knowledge, including discoveries regarding people, culture and society, in addition to the use of such knowledge for new applications.

2. Researchers refers to all research-active members of an institution including employees and doctoral candidates. Persons not directly affiliated with an institution, but who, for purposes of research, make use of or are physically present at the institution, are also included in the term. Visiting researchers or collaborators may also be expected to comply with the policy.

3. Research data refers to all information (independent of form or presentation) needed to support or validate the development, results, observations or findings of a research project, including contextua information. Research data include all materials which are created in the course of academic work, including digitisation, records, source research, experiments, measurements, surveys and interviews. This includes software and code. Research data can take on several forms: during the lifespan of a research project, data 
can exist as gradations of raw data, processed data (including negative and inconclusive results), shared data, published data and Open Access published data, and with varying levels of access, including open data, restricted data and closed data.

Three further approaches, each dealing with different aspects of research data, may help to find the proper definition for individual research institutions:

a. According to the LERU Roadmap for Research Data ${ }^{4}$ (LERU Research

Data Working Group, Advice Paper No. 14 - December 2014):

"Research data, from the point of view of the institution with a responsibility for managing the data, includes: All data which is created by researchers in the course of their work, and for which the institution has a curational responsibility for at least as long as the code and relevant archives/ record keeping acts require, and third-party data which have originated within the institution or come from elsewhere."

b. The Australian Griffith University ${ }^{5}$ presents the following definition ${ }^{6}$ :

"Research data are factual records, which may take the form of numbers, symbols, text, images or sounds, which are used as primary sources for research, which are commonly accepted in the research community as necessary to validate research findings."

b. The University of Minnesota ${ }^{7}$ definition of research data ${ }^{8}$ :

"Research data are data in any format or medium that relate to or support research, scholarship, or artistic activity. They can be classified as:

- Raw or primary data: information recorded as notes, images, video footage, paper surveys, computer files, etc.

- Processed data: analyses, descriptions, and conclusions prepared as reports or papers

- Published data: information distributed to people beyond those involved in data acquisition and administration."

This project has received funding from the European Union's Horizon 2020 research and innovation programme under grant agreement No 654139.

LERU: http://www.leru.org/files/publications/AP14_LERU_Roadmap_for_Research_data_final.pdf; last accessed 14/2/17.

Griffith University: https://intranet.secure.griffith.edu.au/_data/assets/pdf_file/0003/716106/ARI_DataManagement_Pt1_Apr2015.pdf; last accessed 14/2/17.

6 See also: Ingrid Dillo - Data Archiving and Networked Services (DANS), Certification as a means of providing trust, Florence, Fondazione Rinascimento Digitale, 2012 and Data Management at UTSA.

University of Minnesota: https://www.lib.umn.edu/datamanagement/whatdata ; last accessed 14/2/17

See also: Ingrid Dillo - Data Archiving and Networked Services (DANS), Certification as a means of providing trust, Florence, Fondazione Rinascimento Digitale, 2012. 